\begin{tabular}{ll}
\hline JURNAL PELITA PENDIDIKAN & $\begin{array}{l}\text { Volume } 8 \text { Nomor } 4 \text { (2020), } 230 \text { - } 236 \\
\text { Jurnal Pelita Pendidikan }\end{array}$ \\
Journal of Biology Education \\
https://jurnal.unimed.ac.id/2012/index.php/pelita/index \\
eISSN: $2502-3217$ pISSN: $2338-3003$
\end{tabular}

\title{
KONTRIBUSI MICRO TEACHING TERHADAP KOMPETENSI PEDAGOGIK DAN KOMPETENSI PROFESIONAL MAHASISWA PENDIDIKAN BIOLOGI DALAM MENGAJAR TERBIMBING
}

\author{
Cicik Suriani ${ }^{*}$, Rafi Alwaliyyu \\ Program Studi Pendidikan Biologi, FMIPA, Universitas Negeri Medan, Medan Jl. Willem Iskandar Psr. V Medan \\ Estate, Medan, Indonesia, 20221 \\ *Korespondensi Author: cicik.pendbio@gmail.com
}

\section{INFOARTIKEL}

\section{Riwayat artikel:}

Diterima 10 Desember

2020

Revisi 17 Desember

2020

Dipublikasikan 28

Desember 2020

\section{Kata kunci:}

Micro Teaching, Kompetensi

Pedagogik, Kompetensi

Profesional, Mengajar

Terbimbing

\begin{abstract}
ABSTRAK
Penelitian ini bertujuan untuk mengetahui tanggapan mahasiswa mengenai kontribusi Micro Teaching terhadap kompetensi pedagogik dan kompetensi profesional mahasiswa Pendidikan Biologi dalam Mengajar Terbimbing. Penelitian ini merupakan penelitian ex post facto dengan metode penelitian yang bersifat deskriptif kuantitatif jenis studi korelasional. Tanggapan mahasiswa terhadap pelaksanakaaan mata kuliah Micro Teaching sebesar $73 \%$ pada kategori tinggi yang tersebar pada indikator-indikator mata kuliah Micro Teaching. Tanggapan mahasiswa terhadap pelaksanaan mata kuliah Mengajar Terbimbing sebesar 62,5\% pada kategori tinggi yang tersebar pada indikator-indikator mata kuliah Mengajar Terbimbing. Ada hubungan yang signifikan antara tanggapan mahasiswa terhadap pelaksanaan mata kuliah Micro Teaching dengan tanggapan mahasiswa terhadap pelaksanaan Mengajar Terbimbing dengan koefisien korelasi sebesar 0,82 , uji t yaitu thitung $(11,28)>$ ttabel $(1,999)$ dan kontribusi Micro Teaching terhadap pelaksanaan Mengajar Terbimbing sebesar $67 \%$.
\end{abstract}

\begin{abstract}
This study aims to determine student responses regarding the contribution of Micro Teaching to the pedagogical competence and professional competence of Biology Education students in Guided Teaching. This research is an ex post facto research with a descriptive quantitative research method of correlational study type. The response of students to the implementation of the Micro Teaching course was $73 \%$ in the high category which was spread on indicators of the Micro Teaching course. Student responses to the implementation of the Guided Teaching course amounted to $62.5 \%$ in the high category spread across indicators for the Guided Teaching course. There is a significant relationship between student responses to the implementation of the Micro Teaching course with student responses to the implementation of Guided Teaching with a correlation coefficient of 0.82 , the $t$ test is $t$ count (11.28)> $t$ table (1.999) and the contribution of Micro Teaching to the implementation of Guided Teaching $67 \%$.
\end{abstract}

Copyright (C) 2019 Universitas Negeri Medan. Artikel Open Access dibawah lisensi CC-BY-4.0 (https://creativecommons.org/licenses/by/4.0)

\section{How to Cite:}

Suriani, C., \& Alwaliyyu, R. (2020). Kontribusi Micro Teaching Terhadap Kompetensi Pedagogik Dan Kompetensi Profesional Mahasiswa Pendidikan Biologi Dalam Mengajar Terbimbing. Jurnal Pelita Pendidikan, 8(4), 230-236 


\section{PENDAHULUAN}

Sebagai salah satu Lembaga Pendidikan Tenaga Kependidikan (LPTK) yang mencetak calon guru yang berkualifikasi dibidang studi masingmasing dan khususnya dalam melaksanakan pembelajaran, Universitas Negeri Medan terus berupaya meningkatkan kualitas lulusannya agar dapat menjadi guru yang profesional. Persiapan menghasilkan guru yang profesional melalui proses pelatihan dan edukasi sangat krusial untuk dilaksanakan.

Profesionalisme guru merupakan salah satu dari empat kompetensi yang harus dimiliki seorang guru. Kompetensi guru merupakan instrumen yang melibatkan pengetahuan, keterampilan dan sikap yang harus dikuasai guru agar dapat menjalankan tugas secara profesional (Saragih, 2008). Undangundang Republik Indonesia Nomor 14 Tahun 2005 Pasal 8 mengisyaratkan empat kompetensi yang harus dikuasai guru, yaitu (1) kompetensi pedagogik, (2) kompetensi kepribadian, (3) kompetensi sosial, dan (4) kompetensi profesional.

Program yang dijalankan sebagai upaya peningkatan kualitas dan kompetensi calon guru salah satunya adalah dengan memberikan mata kuliah Micro Teaching dan mata kuliah Mengajar Terbimbing. Pemberian mata kuliah-mata kuliah ini dimaksudkan agar dapat meningkatkan profesionalisme mahasiswa calon guru. Sabri (2010) mengatakan bahwa micro teaching bertujuan dalam meyiapkan ilmu, keterampilan, kapabilitas dan sikap mahasiswa agar menjadi guru professional dan menjadikan mahasiswa untuk mampu menganalisis cara maupun sikap mengajar mahasiswa lain, menerapkan keterampilan khusus ketika mengajar, menerapkan teknik mengajar yang bervariasi dengan benar, mampu membangun suasana pembelajaran yang efektif, produktif dan efisien, serta memiliki sikap profesional keguruan.

Kemampuan menguasai keterampilan dasar mengajar bagi mahasiswa calon guru menjadi salah satu syarat penting dalam proses pembelajaran (Helmiati, 2013). Keterampilan dasar mengajar seorang yang harus dimiliki calon guru yaitu: keterampilan membuka dan menutup pembelajaran, keterampilan menjelaskan, keterampilan bertanya, keterampilan memberikan penguatan, keterampilan membimbing diskusi kelompok kecil, keterampilan pengelolaan kelas, dan keterampilan mengadakan variasi (Lubis et al. (2019).

Mata kuliah mengajar terbimbing merupakan bagian dari mata kuliah magang yang diberlakukan sejak tahun 2016 di Universitas Negeri Medan. Program mengajar terbimbing dilaksanakan sebagai upaya peningkatan kompetensi mahasiswa calon guru Biologi khususnya pada kompetensi pedagogik. Kompetensi pedagogik merupakan kemampuan yang harus dimiliki seorang guru agar mampu melaksanakan dan mengatur pembelajaran mulai dari tahap perencanaan, pelaksanaan, evaluasi dan hasil pembelajaran (Evanita, 2013).

Fakta di lapangan memperlihatkan sebagian guru yang belum menguasai kompetensi pedagogik secara utuh (Bhakti, 2016). Lemahnya kompetensi pedagogik guru karena masih kurangnya keterampilan guru dalam mengelola pembelajaran serta minimnya penghayatan guru terhadap profesi keguruan. Mayoritas guru menguasai pengetahuan teori pendidikan dan materi yang diajarkan, akan tetapi masih lemah dalam praktik terutama strategi pembelajaran dan penguasaan psikologi pendidikan (Hasan, 2015). Pengalaman mengajar terbimbing ini diharapkan dapat membentuk mahasiswa menjadi pribadi yang memiliki pengetahuan kependidikan, keterampilan mengajar, mengetahui prinsip guru professional dan dapat mengambil nilai-nilai luhur profesi kependidikan dan menjunjung tinggi nilainilai tersebut.

Ada indikasi yang menunjukkan pelaksanaan mata kuliah Micro Teaching belum memperoleh hasil yang maksimal dan belum cukup untuk membantu mahasiswa saat melaksanakan mata kuliah Mengajar Terbimbing. Hal ini karena masih terdapat banyak kendala pada saat mengajar terbimbing seperti kesulitan dalam mencari materi yang akan diajarkan, kesulitan dalam membuat media, kesulitan dalam menghadapi tingkah laku peserta didik, sarana pembelajaran yang belum memadai, rasa percaya diri yang masih kurang saat menjelaskan materi, penguasaan kelas yang masih kurang, cara mengajar mahasiswa yang masih kaku, kurangnya bimbingan dari guru pamong dan kurangnya kemampuan dalam mengelola kelas dan kurang mampu dalam manajemen waktu saat 
mengajar. Lubis (2017) dalam penelitiannya menyatakan bahwa pelaksanaan micro teaching dan Program Pengalaman Lapangan (PPL) yang dilakukan mahasiswa terkendala pada ketidakmampuan mahasiswa dalam mengelola kelas dan ketidakmampuan mahasiswa dalam membagi waktu ketika mengajar. Simatupang (2018) menguraikan lebih jelas kendala-kendala yang dialami mahasiswa biologi saat perkuliahan Micro Teaching yaitu: (1) pemahaman penyusunan RPP yang belum baik, (2) penguasaan model atau metode dan strategi pembelajaran yang kurang, dan (3) pengalaman mengajar yang belum ada yang berakibat kepada perkuliahan tidak maksimal.

\section{METODE PENELITIAN}

Metode yang digunakan dalam penelitian ini yaitu metode penelitian yang bersifat deskriptif kuantitatif jenis studi korelasional. Populasi dalam penelitian ini adalah seluruh mahasiswa program studi Pendidikan Biologi angkatan tahun 2016, Jurusan Biologi Fakultas Matematika dan IImu Pengetahuan Alam Universitas Negeri Medan yang telah melaksanakan mata kuliah mengajar terbimbing pada tahun ajaran 2018/2019. Sampel yang diambil sebesar 64 mahasiswa yang ditentukan dengan rumus Taro Yamane atau Slovin dan dipilih secara simple random sampling.

Variabel-variabel dalam penelitian ini adalah tanggapan mahasiswa terhadap pelaksanaan mata kuliah Micro Teaching (variabel bebas/variabel $\mathrm{X}$ ) dan tanggapan mahasiswa terhadap Mengajar Terbimbing (Variabel terikat/variabel Y) . Teknik pengumpulan data yang dilakukan adalah dengan cara menyebarkan angket dengan model skala Likert untuk diisi oleh mahasiswa. Data dianalisis menggunakan teknik analisis deskriptif dengan perhitungan persentase dengan rumus:

NP $=\frac{\text { Skor riil }}{\text { Skor } \text { ideal }} \times 100 \%$ (Riduwan dan Akdon, 2015)

Uji-uji yang dilakukan yaitu uji persyaratan data (uji normalitas dan homogenitas), uji koefisien korelasi product moment Karl Pearson, uji hipotesis dan uji determinasi.

\section{HASIL DAN PEMBAHASAN}

Skor tanggapan mahasiswa terhadap pelaksanaan mata kuliah Micro Teaching dapat dilihat pada Tabel 1.

Penjelasan lebih secara visual dari hasil perhitungan tanggapan mahasiswa terhadap pelaksanaan mata kuliah Micro Teaching dapat dilihat pada grafik yang ditunjukkan Gambar 1.

Tabel 1. Skor Tanggapan Mahasiswa Terhadap Pelaksanaan Mata Kuliah Micro Teaching

\begin{tabular}{cccc}
\hline Skor & Frekuensi Absolut & Frekuensi Relatif & Kategori \\
\hline $130-160$ & 47 & $73 \%$ & Tinggi \\
$100-129$ & 17 & $27 \%$ & Cukup \\
$70-99$ & 0 & $0 \%$ & Kurang \\
$40-69$ & 0 & $0 \%$ & Rendah \\
\hline
\end{tabular}

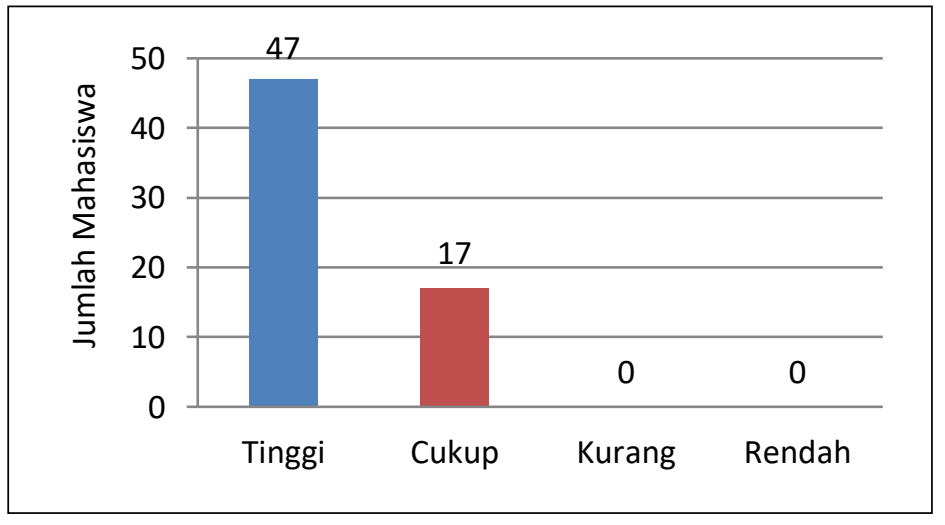

Gambar 1. Grafik Skor Tanggapan Mahasiswa Terhadap Pelaksanaan Mata Kuliah Micro Teaching 
Hasil pada Tabel 1. menunjukkan bahwa sebesar $84 \%$ responden (56 mahasiswa) memberikan tanggapan pada kategori tinggi terhadap pelaksanaan mata kuliah Micro Teaching. Tanggapan dengan kategori tinggi ini tersebar di tujuh indikator dari 8 indikator yang terdapat pada mata kuliah Micro Teaching. Indikator-yang dimaksud yaitu: (1) keterampilan membuka pelajaran, (2) keterampilan menutup pelajaran, (3) keterampilan menjelaskan pembelajaran, (4) keterampilan bertanya, (5) keterampilan memberikan penguatan, (6) keterampilan membimbing diskusi kelompok kecil, (7) keterampilan pengelolaan kelas, dan (8) keterampilan mengadakan variasi. Secara keseluruhan rata-rata tanggapan mahasiswa ini tergolong pada kategori tinggi.

Tingginya tanggapan mahasiswa ini disebabkan karena sebelum pelaksanaan mata kuliah Micro Teaching mahasiswa sudah mendapatkan pengetahuan dan keterampilan terkait kedelapan indikator tersebut. Kedelapan indikator tersebut diperoleh mahasiswa dari mata kuliah Strategi Belajar Mengajar, Perencanaan Pembelajaran Biologi, dan Evaluasi Hasil Belajar. Khusus indikator keterampilan menjelaskan pembelajaran selain diperoleh melalui mata kuliah tersebut, kontennya juga diperoleh melalui mata kuliah-mata kuliah bidang studi biologi. Hal ini sejalan dengan pernyataan Sukmawati (2019) bahwa sebelum melaksanakan mata kuliah Micro Teaching telah ada mata kuliah prasyarat yang harus dituntaskan yaitu mata kuliah SBM, Media Pembelajaran dan Evaluasi.

Skor tanggapan mahasiswa terhadap pelaksanaan mata kuliah Mengajar Terbimbing dapat dilihat pada Tabel 2. Penjelasan lebih secara visual dari hasil perhitungan tanggapan mahasiswa terhadap pelaksanaan mata kuliah Mengajar Terbimbing dapat dilihat pada grafik yang ditunjukkan Gambar 2.

Tabel 2. Skor Tanggapan Mahasiswa Terhadap Pelaksanaan Mata Kuliah Mengajar Terbimbing

\begin{tabular}{cccc}
\hline Skor & Frekuensi Absolut & Frekuensi Relatif & Kategori \\
\hline $130-160$ & 40 & $62,5 \%$ & Tinggi \\
$100-129$ & 23 & $36 \%$ & Cukup \\
$70-99$ & 1 & $1,5 \%$ & Kurang \\
$40-69$ & 0 & $0 \%$ & Rendah \\
\hline
\end{tabular}

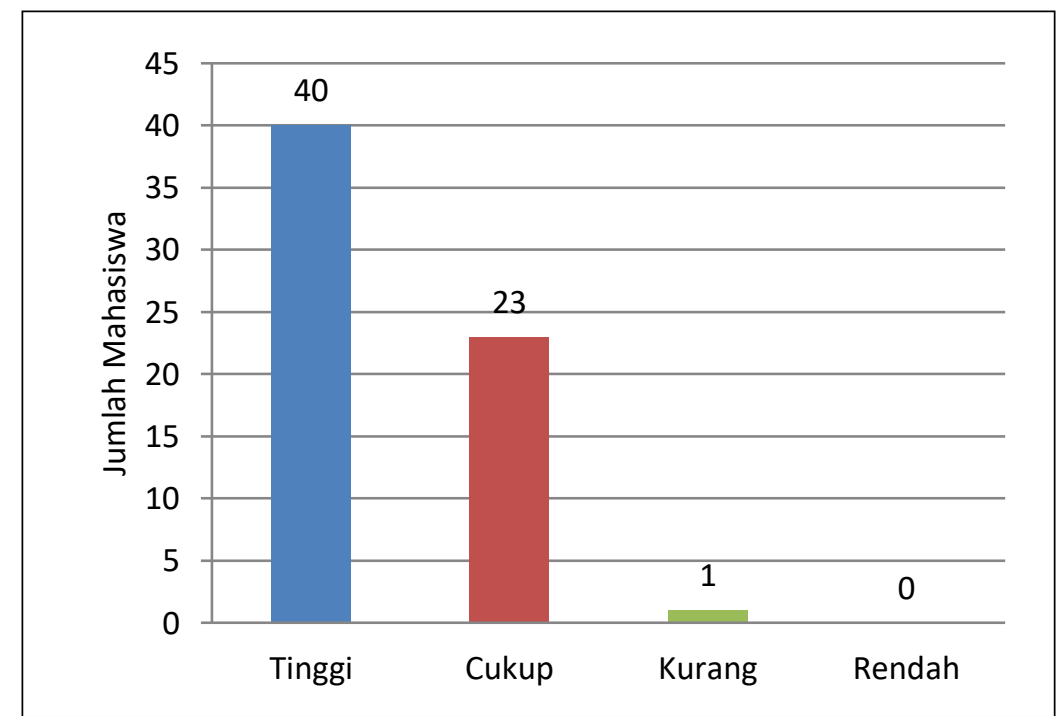

Gambar 2. Grafik Skor Tanggapan Mahasiswa Terhadap Pelaksanaan Mata Kuliah Mengajar Terbimbing.

Hasil untuk tanggapan mahasiswa terhadap pelaksanaan mata kuliah Mengajar Terbimbing diperoleh persentase sebesar $84 \%$ (64 mahasiswa) yang memberikan tanggapan pada kategori tinggi. Tanggapan dengan kategori ini tersebar di tiga belas indikator dari 15 indikator yang terdapat pada mata kuliah Mengajar Terbimbing. Indikator pada ranah kompetensi 
pedagogik yaitu: (1) menguasai karakteristik peserta didik, (2) menguasai prinsip-prinsip pembelajaran yang mendidik, (3) mengembangkan kurikulum, (4) menyelenggarakan pembelajaran yang mendidik, (5) memanfaatkan teknologi informasi dan komunikasi untuk kepentingan pembelajaran, (6) memfasilitasi pengembangan potensi peserta didik, (7) berkomunikasi secara efektif, empatik dan santun, (8) menyelenggarakan evaluasi hasil belajar, (9) memanfaatkan hasil evaluasi untuk kepentingan pembelajaran, dan (10) melakukan tindakan reflektif untuk peningkatan kualitas pembelajaran.

Indikator pada ranah kompetensi profesional yaitu: (1) menguasai materi, struktur, konsep dan pola pikir keilmuan yang mendukung mata pelajaran yang diampu, (2) menguasai standar kompetensi dan kompetensi dasar mata pelajaran yang diampu, (3) mengembangkan materi pembelajaran yang diampu secara kreatif, (4) mengembangkan keprofesionalan secara berkelanjutan, dan (5) memanfaatkan teknologi informasi komunikasi untuk mengembangkan diri. Secara keseluruhan rata-rata tanggapan mahasiswa ini tergolong pada kategori tinggi.

Tingginya tanggapan mahasiswa ini disebabkan karena sebelum pelaksanaan mata kuliah Mengajar Terbimbing mahasiswa sudah mendapatkan pengetahuan dan keterampilan terkait dengan kelima belas indikator tersebut. Indikator pada ranah kompetensi pedagogik diperoleh mahasiswa melalui mata kuliah Micro Teaching, Evaluasi Hasil Belajar, Strategi Belajar Bengajar, Telaah Kurikulum, Perencanaan Pembalajaran Biologi, Perkembangan Peserta Didik, Profesi Kependidikan dan Psikologi Pendidikan.

Indikator pada ranah kompetensi profesional diperoleh mahasiswa dari mata kuliah bidang studi Biologi dan Pengembangan Perangkat Pembelajaran. Sedangkan praktik untuk semua indicator tersebut diperoleh mahasiswa dari mata kuliah Micro Teaching. Hal ini sejalan dengan pernyataan Bhakti (2016) yang menyatakan bahwa pengembangan kompetensi pedagogik mahasiswa dapat dilakukan dengan memberikan mata kuliah kependidikan Psikologi Kependidikan, Pengembangan Kurikulum dan Pembelajaran, Pengantar Ilmu Pendidikan dan Pengembangan Profesi.

Wati (2017) juga menyatakan bahawa mahasiswa Praktik Lapangan Kependidikan sudah dibekali pengetahuan tentang merancang RPP melalui mata kuliah Perencanaan Program Pengajaran Biologi, serta melaksanakan pembelajaran melalui mata kuliah SBM dan Micro Teaching. Mansyur (2017) menyatakan bahwa implementasi dari keempat kompetensi (termasuk kompetensi pedagogik dan kompetensi professional) dapat dilakukan saat praktik micro teaching, dimana perencanaan, pelaksanaan dan evaluasi program pembelajaran serta keterampilan dalam menyampaikan materi merupakan bagian dari kompetensi pedagogik yang juga terdapat pada micro teaching, dan penguasaan materi merupakan bagian dari kompetensi profesional yang juga terdapat pada micro teaching.

Afidah dan Mellani (2018) menyatakan bahwa mata kuliah Telaah Kurikulum berperan penting dalam mempersiapkan mahasiswa yang terampil dalam bertugas untuk merancang perangkat pembelajaran, membentuk mahasiswa yang memiliki tanggung jawab dalam menjalankan tugas dan fungsinya sebagai seorang pendidik. Mata kuliah Psikologi Pendidikan sangat penting bagi mahasiswa calon guru dalam memahami peserta didik sebagaimana yang dikatakan oleh Sanjaya (2019) bahwa Psikologi Pendidikan memiliki tujuan untuk memberikan pemahaman yang baik kepada guru tentang kondisi pendidikan khususnya tentang kondisi peserta didik serta membantu guru dalam melakukan perancangan, perencanaan, penyiapan, pelaksanaan dan pengevaluasian peroses pembelajaran.

Hasil uji hipotesis menunjukkan bahwa $\mathrm{Ha}$ diterima yang berarti ada hubungan antara tanggapan mahasiswa terhadap pelaksanaan mata kuliah Micro Teaching dengan tanggapan mahasiswa terhadap pelaksanaan mata kuliah Mengajar Terbimbing pada mahasiswa Pendidikan Biologi T.A. 2018/2019. Hubungan ini termasuk ke dalam kategori hubungan yang tinggi dengan kontribusi mata kuliah Micro Teaching terhadap pelaksanaan mata kuliah Mengajar Terbimbing sebesar $67 \%$ sedangkan $33 \%$ sisanya dipengaruhi oleh faktor-faktor lain.

Hasil penelitian di atas sejalan dengan penelitian Widiarini (2015) yang menyatakan bahwa ada hubungan yang positif dan signifikan antara hasil belajar micro teaching dengan hasil belajar PPL II. Senada dengan penelitian Sohibun (2017) yang menyatakan bahwa terdapat hubungan yang tinggi dan signifikan antara mata kuliah Profesi Kependidikan dan Micro Teaching terhadap PPL dengan sumbangan kontribusi persentase yang tinggi dari tiap mata kuliah. Tingginya kontribusi mata kuliah Micro Teaching terhadap suksesnya pelaksanaan Mengajar Terbimbing sangat beralasan karena banyak keterampilan yang dapat dikuasai mahasiswa jika Micro Teaching dilaksanakan dengan baik. Sebagaimana yang dikatakan oleh Widiarini (2015) bahwa pelaksanaan micro teaching yang baik dan 
efektif akan meningkatkan kemampuan mengajar mahasiswa ketika PPL di sekolah.

Ulasan-ulasan di atas dapat memberikan pemahaman bahwa Micro Teaching memiliki peran penting dalam mempersiapkan mahasiswa Pendidikan Biologi dalam melaksanakan Mengajar Terbimbing. Peranan ini tampak jelas karena kedudukan Micro Teaching sebagai bekal untuk mempersiapkan mahasiswa dalam mengajar secara langsung di sekolah. Sebagaimana yang dinyatakan oleh Novianingtyas (2018) bahwa micro teaching memberikan peran yang sangat penting bagi keberhasilan magang 3 karena bekal mengajar dan teori-teori kependidikan yang diperoleh dapat terapkan dan ditingkatkan pada saat magang 3. Lebih lanjut Shah dan Masur (2011) mengatakan bahwa peran micro teaching yang terus dilatih akan berakibat pada kinerja guru yang relatif lebih baik sehingga program pelatihan untuk melayani guru dalam menguasai metode pengajaran harus terus dibangun. Proses mengajar mahasiswa di sekolah dapat berjalan dengan baik dan lancar karena maksimalnya kesiapannya untuk mengajar. Jelas karena keterampilan mengajar yang sudah diperoleh dari mata kuliah Micro Teaching. Kesiapan mengajar maksimal ini berkaitan dengan persepsi yang baik terhadap micro teaching. Sebagaimana yang dikatakan Azizah dan Rahmi (2019) bahwa jika persepsi mahasiswa terhadap peranan micro teaching semakin baik akan berakibat kepada kesiapan mengajar mahasiswa yang semakin tinggi.

\section{KESIMPULAN}

Tanggapan mahasiswa terhadap pelaksanakaaan mata kuliah Micro Teaching sebesar $73 \%$ pada kategori tinggi dan ini tersebar pada indikator-indikator yang terdapat pada mata kuliah Micro Teaching. Tanggapan mahasiswa terhadap pelaksanaan mata kuliah Mengajar Terbimbing sebesar $62,5 \%$ pada kategori tinggi dan ini tersebar pada indikator-indikator yang terdapat pada mata kuliah Mengajar Terbimbing. Kemudian ada hubungan yang kuat dan signifikan antara tanggapan mahasiswa terhadap pelaksanaan mata kuliah Micro Teaching dengan tanggapan mahasiswa terhadap pelaksanaan Mengajar Terbimbing dengan koefisien korelasi sebesar 0,82, uji t yaitu thitung $(11,28)>$ ttabel
$(1,999)$ dan kontribusi Micro Teaching terhadap pelaksanaan Mengajar Terbimbing sebesar $67 \%$ sedangkan $33 \%$ sisanya dipengaruhi oleh factor lain.

\section{DAFTAR PUSTAKA}

Afidah, M., dan Mellani, R., (2018), Persepsi Mahasiswa Pendidikan Biologi Terhadap Mata Kuliah Telaah Kurikulum Pada Pelaksanaan PPL T. A. 2017/2018, BioLectura: Jurnal Pendidikan Biologi, 5(2): $140-149$.

Bhakti, C. P., dan Maryani, I., (2016), Peran LPTK dalam Pengembangan Kompetensi Pedagogik Calon Guru, Jurnal Penidikan (Teori dan Praktik), 1(2): 98 - 106.

Azizah, N., dan Rahmi, E., (2019), Persepsi Mahasiswa Tentang Peranan Mata Kuliah Micro Teaching Terhadap Kesiapan Mengajar Pada Mahasiswa Pendidikan Ekonomi UNP, EcoGen, 2(2): 197 - 205.

Bhakti, C. P., dan Maryani, I., (2016), Peran LPTK dalam Pengembangan Kompetensi Pedagogik Calon Guru, Jurnal Penidikan (Teori dan Praktik), 1(2): 98-106.

Evanita, E. L., (2013), Analisis Kompetensi Pedagogik dan Kesiapan Guru Sekolah Menengah Atas dalam menukung Impementasi Kurikulm 2013, Doctoral Dissertation, Universitas Negeri Semarang.

Hasan, I., (2015), Pengembangan Kurikulum LPTK (Penyiapan Calon Guru PAI) Berbasis KKNI, Islamadina, 14(1): 24-40.

Helmiati, (2013), Micro Teaching: Melatih Keterampilan Dasar Mengajar, Aswaja Pressindo, Yogyakarta.

Lubis, A., Hanafi, dan Siregar, R. A., (2019), Sistem Pengelolaan Microteaching dengan Siklus Perencanaan, Pelaksanaan, Evaluasi, Pengendalian, Peningkatan (PPEPP) untuk Meningkatkan Keterampilan Mengajar Mahasiswa Calon Guru, CV Berkah Prima, Padang.

Lubis, L. A. A., (2017), Persepsi Mahasiswa Biologi Universitas Negeri Medan Terhadap Mata Kuliah Microteaching Pada Pelaksanaan 
Program Pengalaman Lapangan Tp 2016/2017, Doctoral dissertation, UNIMED, Medan.

Mansyur, (2017), Keterampilan Dasar Mengajar dan Penguasaan Kompetensi Guru (Suatu Proses Pembelajaran Micro), el-Ghiroh, 7(1): $130-147$.

Novianingtyas, D., (2018), Peran Microteaching Terhadap Keberhasilan Magang 3 Mahasiswa Program Studi Pendidikan Akuntansi Universitas Muhammadiyah Surakarta Tahun Ajaran 2014, Doctoral dissertation, Universitas Muhammadiyah Surakarta.

Riduwan, dan Akdon, (2015), Rumus dan Data dalam Aplikasi Statistika, Alfabeta, Bandung.

Sabri, A., (2010), Strategi Belajar Mengajar Micro Teaching, Quantum Teaching, Ciputat.

Sanjaya, P., (2019), Peranan Psikologi Pendidikan Sebagai Kompetensi Dasar Pendidik dan Tenaga Kependidikan, Guna Widya: Jurnal Pendidikan Hindu, 4(2): 47 - 56.

Saragih, A. H., (2008), Kompetensi Miniimal Seorang Guru dalam Mengajar, Jurnal Tabularasa, 5 (1): 23-34.

Shah, S. M. H., dan Masrur, R., (2011), Impact of Micro Teaching Skills on the Performance of Primary School Teachers, Gomal University Journal of Research, 27(1): 15 29.

Simatupang, H., dan Aryeni, (2018), Model Pendekatan Lesson Study untuk Meningkatkan Keterampilan Mengajar Mahasiswa pada Mata Kuliah Micro Teaching, Jurnal Biolokus, 1(2): 77-83.

Sohibun., Febriani, Y., dan Maisaroh, I., (2017), Peranan Mata Kuliah Profesi Kepenidikan dan Microteaching Terhadap Kompetensi Profesional Mahasiswa PPL Fisika, Jurnal Keguruan dan Ilmu Tarbiyah, 02(1): 57-65.

Sukmawati, Rika. (2019) Analisis Kesiapan Mahasiswa Menjadi Calon Guru Profesional Berdasarkan Standar Kompetensi Pendidik. Jurnal Analisa, 5(1): $95-102$
Undang-undang Republik Indosesia Nomor 14 Tahun 2005 Tentang Guru dan Dosen.

Wati, D. D. E., (2017), Persepsi Guru Pamong Terhadap Profesional Mahasiswa Praktek Lapangan Kependidikan, BioCONCETTA Jurnal Biologi dan Kependidikan Biologi, 3(2): $9-21$.

Widiarini, I. A. K., Tripalupi, L. E., dan Meitriana, M. A., (2015), Hubungan Hasil Belajar Mata Kuliah Micro Teaching (PPL I) Dengan Hasil Belajar Program Pengalaman Lapangan (PPL II) Mahasiswa Jurusan Pendidikan Ekonomi pada Semester Genap Tahun Akademik 2013/2014 dan Semester Ganjil Tahun Akademik 2014/2015, Jurnal Jurusan Pendidikan Ekonomi, 5(10). 